\title{
THE GENERAL FORM OF THE OPERATION IN WITTGENSTEIN'S TRACTATUS
}

\author{
Göran SUNDHOLM \\ University of Leyden
}

Propositions and operations both play a central role in the Philosophy of Logic as set out in Wittgensteins Tractatus. ${ }^{1}$ The general propositional form is amply treated of both in the work itself and in the substantial secondary literature. ${ }^{2}$ The general form of an operation, on the other hand, has, to the best of my knowledge, received no scholarly attention and it is dealt with only in thesis 6.01 and its preamble 6.002 . Accordingly it is the purpose of the present paper to discuss the proper interprertation of this thesis which reads:

Die allgemeine Form der Operation $\Omega^{\prime}(\bar{\eta})$ ist also: $[\bar{\xi}, N(\bar{\xi})]^{\prime}(\eta)$ $(=[\bar{\eta}, \bar{\xi}, \mathbf{N}(\bar{\xi})])$.

Das ist die allgemeinste Form des Überganges von einem Satz zum anderen.

In view of 6.002 , the general propositional form will have to be explained, as well as the notion of an operation. Furthermore, certain

1. C.K. Ogden (trans.), Routledge and Kegan Paul, London, 1922. New translation by D. Pears and B. McGuinness, Routledge and Kegan Paul, London, 1961 (2nd ed.1971). The "Kritische Edition" by Schulte and McGuinness, Suhrkamp, Frankfurt a. M., 1989, which contains crossreferences to the Notebooks and the Prototractatus as well as the complete text of the Prototractatus, proved most useful during the preparation of the present paper.

2. $4.5,4.53,5,5.47,5.5$ and 6. The commentaries G.E.M. Anscombe, An Introduction to Wittgenstein's Tractatus, Hutchinson, London, 1959; Max Black, A Companion to Wittgenstein's Tractatus, Comell U.P. 1964; R.J. Fogelin, Wittgenstein, Routledge, London, 1976 and H.N. Mounce, Wittgenstein's Tractatus. An Introduction, Blackwell, Oxford, 1981 are all useful here. Particularly relevant are P.T. Geach, "Wittgenstein's operator N", Analysis 41(1983), pp.16871, and S. Soames, "Generality, Truthfunctions and Expressive Capacity", Phil. Review XCII (1983), pp. 573-589. 
specifically Tractarian notational devices demand clarification. Inspection of thesis 6.01 shows that we have to deal with at least the following:

- the joint negation operation $\mathrm{N}$

- the elevated comma

- the equality sign

- round Klammerausdrücke

- square Klammerausdrücke with two, respectively, three arguments

- the bar notation.

Owing to the firm internal cohesion of the Tractatus, though, the required explanations will have to touch upon a considerably wider range of matters.

Our first task is to treat of the formal concept operation. It is introduced in the course of an alternative description of the Formenreihen. ${ }^{3}$ Originally, in thesis 4.1252 , a series of forms is explained as a series ordered by an internal relation. This explanation permits two readings: one Russellian and one Fregean. The former is, prima facie, the natural one: the internal relation itself is a strict ordering of the terms in the series, that is, a series also in the terminology of Principia Mathematica. ${ }^{4}$ The Fregean option, on the other hand, renders 'is ordered by' as gets its order from. Thus the sequence of terms itself is a PM-series, but the internal relation is not an ordering relation for the series; it only generates such an ordering.

In view of the alternative characterization of the notion of a Formenreihe offered in thesis 4.1273 the Fregean reading deserves preference. There a series of forms is determined by laying down its first term and a general operation producing the next term from its predecessor. Thus the terms of the series $S$, with order generated from the internal relation $\Omega$, can all be obtained through successive

3. The English translations offered in the editions mentioned in f.n. 1 are, repectively, formal series and series of forms.

4. A.N. Whitehead and Bertrand Russell, PrincipiaMathematica(P.M.), Vols. I-III, Cambridge U.P., 1910-1913, Vol.II, Part V, p. 513 ff. 
applications of the operation $\mathrm{O}$. The relation $\Omega$, however, must be many-one in order that the two characterizations of Formenreihen match and that the operation $\mathrm{O}$ may be legitemately introduced:

(*) $\mathrm{OS}_{1}=\mathrm{S}_{2}$ iff $\mathrm{S}_{1} \Omega \mathrm{S}_{2}$.

Thus $\Omega$ itself cannot be a PM-series: a many-one relation cannot in general be transitive and transitivity is a mandatory requirement for any sort of ordering. This reading is leant further support in thesis 5.232:

Die interne Relation, die eine Reihe ordnet, ist äquivalent mit der

Operation, durch welche ein Glied aus einem anderen entsteht.

The ancestral $\Omega *$ of $\Omega$ is a PM-series with the series $S$ as its field, however, and this can be taken as a precise expression of the sense in which the internal relation $\Omega$ orders the terms of $S$.

The grounds for an attribution to Frege, rather than to Russell,of the preferred, latter reading can be found in his tratment of the ancestral and like matters, which bears the apt title "Einiges aus einer allgemeinen Reihenlehre". ${ }^{5}$ In the development of his theory Frege has occasion to consider a two-place propositional function $f(\Gamma, \Delta)$ for which he offers the following renderings:

" $\Delta$ ist Ergebnis einer Anwendung des Verfahrens $f$ auf $\Gamma$ " oder durch ... " $\Delta$ steht in der f-Beziehung zu $\Gamma$ ”..., welche Ausdrücke als gleichbedeutend gelten sollen. ${ }^{6}$

When we read "operation" for "Verfahren" and "internal relation" for "Beziehung" the result is a neat reformulation of thesis 5.232 quoted above.

In the theses referred to and other similar passages, e.g. 5.23 and 5.251 , Operation is used in the sense of a general method or recipe for action rather than for the operational deed itself. The latter, on the other hand, must be meant in those passages, among which 5.21 and 5.234, where there is talk of the result of an operation. A simple way to resolve this ambiguity is to reserve Operation for the method

5. Begriffsschrift, Jena 1879 , part III.

6. Op.cit, f.n. 5, p. 57. 
and use Anwendung der Operation for the operational deed. ${ }^{7}$

The Tractarian treatment of operations is largely contained in the theses 5.21 to 5.254, inclusive, which all serve to comment upon thesis 5.2:

Die Strukturen der Sätze stehen in internen Beziehungnen zueinander. An operation gives expression to such an internal relation between Sätzen $(5.21,5.22)$ much in the same way that a material property, or relation, is expressed by a material function (4.1276). The (method of) operation which gives expression to an internal relation between Sätzen provides the type of action that has to be carried out on a Satz in order to produce the internally related Satz. Strictly speaking (3.11), a Satz is a Satzzeichen in use, in a projective relation to the world. The sense of 'is' involved here is that of representation; the Satz is a Zeichen in the same way that the King in Chess is a piece of wood. The Satzzeichen possesses structure that can be internally related to other structures and hence an operation would be carried out on the Satzzeichen. ${ }^{8}$ Wittgenstein is quite explicit on this point: an operation acts on the signs. ${ }^{9}$

7. Several ion-words show similar ambiguities in the Tractatus. Funktion is ambiguous between, on the one hand, 'function of' and, on the other, the Fregean unsaturated notion. Similarly, Konfiguration is ambiguous between the pattern of configuration and the structure thus configurated. Karl-Heinz Hülser, Wahrheitstheorie als Aussagetheorie, Forum Academicum, Königstein/Ts., 1977, p. 34, f.n. 21 and pp. 112-3, is most illuminating here.

8. James Griffin, Wittgenstein's Logical Atomism, 2nd ed., O.U.P., 1965, Ch. $\mathrm{X}$, gives a clear presentation of the interrelations between Satz, sinnvoller Satz and Satzzeichen. Hidé Ishiguro, "Representation: An Investigation Based on a Passage in the Tractatus", in: B. Freed et al. (eds.), Forms of Representations, North-Holland, Amsterdam, 1975, pp.189-202, is particularly helpful on the 'is' of representation.

9. Notebooks, 22. 11. 16.. Contemporary logical terminology differentiates between functions and functors. The former are entities, whereas the latter are pieces of notation which refer to functions. The application of a function to an argument is syntactically couched in terms of the juxtaposition of a singular term to a functor. Thus one might expect Wittgenstein to use operator in place of operation. This, however, would be doubly wrong. First, it would point in the direction of a violation of thesis 5.25 , since functions and operations would be treated on par as the operators would express operations in the same way that functors ex- 
The restriction of operations to a field of only Sätze may well serve to explain the emphasis Wittgenstein lays on the difference between functions and operations $(5.25,5.251)$. There are Tractarian functions whose range of values consists of Sätze $(3.318,4.24)$, but these Sätze cannot serve as arguments for the functions whose values they are. A Satz which results from an application of an operation, on the other hand, may equally well serve as a base for yet further applications of the same operation: the range of an operation may be included in its domain.

Russell used an elevated inverted comma notation

$$
R \cdot y=(\imath x)(x R y) D f .
$$

for descriptive functions and clearly Wittgenstein's elevated comma is related to Russell's. ${ }^{10}$ In $(*)$ above the basic connection between operations and internal relations is brought out; using the elevated comma it may be reformulated :

$$
\text { (**) } \Omega^{\prime} \mathrm{S}_{1}=\mathrm{S}_{2} \text { iff } \mathrm{S}_{1} \Omega \mathrm{S}_{2} \text {. }
$$

Thus the elevated comma provides a means with which to emphasize the relational origin of operations just in the same way that Russell's elevated inverted comma shows the relational origin of descriptive functions. Wittgenstein could not make use of the latter in view of the order of arguments: it is the opposite from what he needs and this might explain his inversion of Russell's sign. Yet a further reason for this notational change lies in the circumstance that the descriptive functions of Russell are all material functions and therefore unsuitable as expressions for Wittgenstein's operations that result from internal relations.

One must note here that not all Tractarian signs for operations carry an elevated comma, $c f$. for instance thesis 5.502 and many

press functions. Secondly, the operation already acts on the signs, whence it would entail a superfluous doubling of entitites acting on the syntactic level. The action of the operation $\mathrm{N}$ is as follows: juxtapose the letter " $\mathrm{N}$ " with a notation for a range of bases. The result is a sign which expresses a Satz that is true provided all the Sätze in the range of bases are false.

10. P.M., op.cit., f.n. 4,Vol. I, * 30.01, p. 245. 
other places where truth-operations are employed. The truth-operations in general, and in particular the operation $\mathrm{N}$, are, however, prima facie not given in terms of internal relations, but through truth-value considerations and this difference in conceptual origin might serve to explain the notational differences: the elevated comma is reserved to those cases where the operation is straightforwardly obtained from an internal operation. The other way of introducing operations via truth-table considerations poses questions of legitimacy, though: is not the first method, ultimately couched in terms of internal relations between the structures of Satzzeichen, more general than the latter? First, note that the other direction poses no problem: given that the truth-table itself may be viewed as as a Satzzeichen (4.442) a truth-value explanation of an operation automatically provides an internal relation between the relevant Satzzeichen. For the other direction we have to consider an operation introduced by means of an internal relation and reformulate it in terms of truth-value considerations. In order to see that this is possible we need to refine a point made above concerning the respective roles of Satz and Satzzeichen: an operation acts on the sign serving as a symbol. This general point applied to Sätze yields that the operations on Sätze act on the Satzzeichen serving as Sätze. Thus not necessarily every structural feature of the Satzzeichenfacts will serve to yield an internal relation between Sätze: it is a possibility that two Satzzeichen-facts are internally related in a certain way without any matching internal relation between the Sätze expressed. A Satz is a Satzzeichen in a projective relation to the world, which restricts reality to yes or no $(3.12,4.023)$. Thus, only such structural features (of a Satzzeichen serving as Satz) that are relvant for the Satz's being able to limit reality to yes or no serve to determine internal relations between Sätze and the ensuing operations. In other words, only truth-conditionally relevant features may be used to determine internal relations between Sätze, rather than between facts which happen to serve as Satzzeichen and where any structural features will do to specify an internal relation. Thus the legitimacy of the truth-value method can be upheld: it allows for no more and no fewer operations than the method via internal relations. ${ }^{11}$

11. It is worth noting that the Prototractatus systematically uses sign where the 
The operation defined at (**) applies to one base only, but this is not an essential feature of operations. The foremost example of an operation that we have to consider, namely the joint negation operation $\mathrm{N}$ is applicable to arbitrary many bases from none to an unlimited number $(5.5,5.502)$. The resulting sentential sign expresses a Satz which is true precisely when all the bases in question are false. These bases are given via Klammerausdrücke

where " $\xi$ " is a variable ranging over the relevant Sätze. Wittgenstein is at pains to stress that it is immaterial how this range of Sätze is described $(3.317,5.501)$ : the only important thing to ensure is that all values of the variable $x$ are taken into account and the superscript bar is meant to emphasize this (5.501). Wittgenstein considers three illustrative ways of how to give the range of a Klammerausdruck variable, but, given his remarks on the freedom as to the presentation of bases, these cannot be considered exhaustive.

The first of these is very simple and, in fact, it only makes superficial use of a variable. This is the case where the range in question consists of a finite unordered list of Sätze; clearly such a list itself will serve as well as any variable to describe the relevant bases for the application of $\mathrm{N}$. The second case is also fairly straightforward, but heated controversy has arisen in its wake. Here the variable in question occurs in a propositional Urbild:

\section{$\mathbf{f}(\mathbf{x})$}

which serves to delimit all the Sätze that are instances hereof. In thesis 5.52 this is used to provide a quantifier-notation, which unfortunately does not allow for necessary scope-distinctions, as has been stressed by Fogelin. ${ }^{12}$

Tractatus has symbol. Some relevant theses from the earlier manuscript are: $3.20121,3.0122,4.102263,5.315,5.3251,5.405$ and other places. Thus the insights concerning the proper nature of symbolism seem to be rather late.

12. "Wittgenstein's operator N", Analysis 42 (1982), pp. 124-127, with reply by Geach. 
Geach and Soames have suggested simple, basically equivalent, remedies which certainly seem permissible, given the theses just cited to the effect that it is immaterial what notational devices are used to specify the variable-ranges in the Klammerausdrücke. ${ }^{13}$ On the other hand, it is equally clear that Fogelin, who rejects the Geach-Soames emendation, is on strong ground when he emphasizes that the decidability of logical truth is a, if not the, central feature of the Tractarian philosophy of logic $(6.113,6.126,6.1262)$ : it must be possible to decide mechanically, by syntactic calculation am Symbol allein, whether a Satz is tautological or not. According to the Theorem of Church, the scope-discerning devices of Geach and Soames do not in general admit of such decidability. This, however, is not the last word on the matter, since, on behalf of Geach and Soames, we may remark that Wittgenstein clearly intends the expressive capacities of the Tractarian language to encompass also multiple generality of first and higher order (which serves to rule out decidability). This is conclusively brought out in thesis 6.1232 where the Axiom of Reducibility, which employs such quantification, is singled out as a Satz. Thus I would hold that both sides of the dispute are right and that the error lies in a fundamental inconsistency embedded in the Tractatus itself.

Wittgenstein's third example is perhaps the most interesting. Here one gives a "formal law", according to which the Sätze of the range in question are generated and in this case, Wittgenstein states, the members of the range constitute a series of forms. This would seem to indicate that by "formal law" is meant a specification of a first term and a means for obtaining latter terms from previous ones. Thus we are straightforwardly led into consideration of the threeplace Klammerausdrücke from thesis 5.2522. This is a diffenent type of bracket expression from the one we encountered in thesis 5.501 and which made use of round brackets, in conjucntion with Greek variables, in order to specify ranges of Sätze which are to serve as bases for applications of suitable operations. Here the bracket expression makes use of square brackets which essentially serve as a notation for an iteration-functional on expressions. Given a term a and an operation $\mathrm{O}$ for producing expressions from expressions, the Klammerausdruck

13. Op.cit., f.n. 2. 


$$
[\mathrm{a}, \mathrm{x}, \mathrm{Ox}]
$$

indicates the general term in the series of forms which consists exclusively and entirely of the iterations of $\mathrm{O}$ with respect to a: a, $\mathrm{Oa}, \mathrm{OOa}, \mathrm{OOOa}, . .$. , and so on.

We may compare this with the use of an arithmetical iterationfunctional $I t(m, g)$ of one number-argument $\mathrm{m}$ and one function argument $g$. Given a natural number $k$ and a function with $f(x)$ as value for number-argument $\mathrm{x}$,

$$
\text { It }(k, \lambda x f(x))
$$

is a function satifying the recursion equations

$$
\begin{aligned}
& \text { It }(\mathrm{k}, \lambda \mathrm{xf}(\mathrm{x}))(\mathrm{O})=\mathrm{k} \\
& \mathbf{I t}(\mathrm{k}, \lambda \mathrm{xf}(\mathrm{x}))(\mathrm{n}+1)=\mathrm{f}(\mathbf{I t}(\mathrm{k}, \lambda \mathrm{xf}(\mathrm{x}))(\mathrm{n})) .
\end{aligned}
$$

Accordingly the value range of this function will be:

$$
k, f(k), f(f(k)), f(f(f(k))), \ldots, \text { and so on. }
$$

Pursuing this analogy with the arithmetical iteration-functional we see that the three arguments of the three-place square brackets properly speaking ought to be only two and that the task of the second argument, in relation to the third, really is that of serving as a mark of bondage. A more adequate square bracket notation is accordingly provided by

$$
[\mathrm{a}, \mathrm{O}] \text {, }
$$

where $\mathrm{a}$ is a term and $\mathrm{O}$ the general operation in question, or, making the variable-binding explicit,

$$
[\mathrm{a}, \lambda \mathrm{xOx}] \text {. }
$$

In the case of arithmetic it is known that, modulo a suitable choice of initial functions, the scheme of iteration suffices to give all primitive recursive definitions. ${ }^{14}$ No comparable reduction is known for the

14. Raphael M. Robinson, "Primitive Recursive Funtions", Bulletin of the 
case of inductive generation of syntactic forms and the question immedeately arises whether the limitations on Wittgenstein's inductions proves too restrictive: does iteration of an operation suffice to generate all Sätze? Wittgenstein clearly intends the answer to be positive; indeed, thesis 6 , which represents the culmination of the technical development of the positive side of the Tractatus, is intended as a demonstration of how the Sätze constitute a Formenreihe by being generated from elementary Sätze using the operation N:

Die allgemeine Form der Wahrheitsfunktion ist: $[\bar{p}, \bar{\xi}, N(\bar{\xi})]$.

Dies ist die allgemeine Form des Satzes.

In the explanation of the square brackets at 5.2522, Wittgenstein is at pains to emphasize the homogeneity of arguments, even to the extent of misrepresenting the variable-binding role of the middle argument. Here in thesis 6 , on the other hand, homogeneity is violated in a most blatant way: the third argument-place is taken by a result of an application of the joint negation operation $\mathrm{N}$ to a certain range of Sätze, that is, by a Satz, whereas the other two places are taken by ranges of Sätze, whether elementary or not. It is incumbent on any Tractatus interpretation to try to make sense of this deviant use of the square brackets. In my opinion this is an insoluble task; their use in thesis 6 represents a tacit break with the conventions laid down in 5.2522. In particular, the inductions employed at 6 are considerably more complex than mere iterations.

The first difficulty one encounters when dealing with thesis 6 is how to interpret the superscript bar in connection with the letter ' $p$ '. The latter has, after all, a fair number of uses in the Tractatus. It serves, for instance, to indicate arguments of truth-functions, or, perhaps more accurately phrased, the bases of truth-operations, (e.g. 5.02) as well as facts (e.g. 5.43). Furthermore, it most commonly indicates a fixed, but further unspecified Satz (4.061 and many other places), sometimes with the further demand that the Satz indicated has to be an Elementarsatz (e.g. 4.31). None but the last of these various types of uses offers a serious alternative for the interpetation of thesis 6, though; in the gloss offered in 6.001 we learn that thesis 6 claims nothing but that any Satz is the result of successive

American Mathematical Society 53(1947), pp. 925-942. 
applications of the operation $\mathrm{N}$ on Elementarsätze.

The present use of the bar is not covered by the explantion offered in 5.501, where its use is laid down only in connection with round brackets and Greek variables. It would be far too restrictive, though, to treat 'p' as standing for one fixed Elementarsatz; in that case one could not even obtain the Satz p\&q, where q is another Elementarsatz. The Greek letter ' $\xi$ ' is characterized as a Satzvariable in 5.502 and it seems rasonable here to view also 'p' as a variable, namely as one ranging over Elementarsätze. The interpretational issue concerning the letter ' $p$ ' in conjunction with a superscript bar thus comes down to the problem of determining the permissible ranges of Elementarsatzvariable. The phrase 'auf die Elementarsätze', from the gloss 6.001 mentioned above, could be taken to indicate that the only range allowed is that of all Elementarsätze. Again, such a reading would be far too restrictive. The result of an application of $\mathrm{N}$ to this single range yields a fixed $\mathrm{Satz} \mathrm{S}$ as its reult and it is not to be seen how to obtain from this, e.g. the Satz p\&q already used as an example above, by means of further operations on $\mathrm{N}$. Thus we have to consider the option that the use of ' $\bar{p}$ ' is analogous to that of ' $(\xi)$ ', only now confined to Elementarsätze. It is a moot point, however, whether such a use of an Elementarsatzvariable is allowed. A formal concept is immediately given with an object falling under it (4.12721) and a variable is a sign of a formal concept (4.1271); thus an object falls under a certain formal concept precisely when it is a value of a corresponding variable which serves as a sign for the formal concept in question. But plainly an Elementarsatz is a Satz (4.21), so what concept would be signified by an Elementarsatzvariable? The formal concept Satz is given with any value of an Elementarsatzvariable and it is not at all clear whether a variable can serve as a sign for more than one formal concept. The difficulty is that the status of subconcepts is unclear for formal concepts. Those occurrences of the letter 'p' which are candidates for service as Elementarsatzvariable are too nondescript to settle the issue one way or the other; for example, does 'p' so serve in thesis 4.24? In spite of these difficulties, if we want to make sense of the occurrence of ' $p$ ' in thesis 6 , the only viable alternative seems to be to take it as part of a variable-notation for classes of Elementarsätze. 
The admissible means for presenting such classes then become quite relevant for the proper interpretation of thesis 6 . That thesis is the culmination of a line of thought which is first adumbrated at 5.1, while 5.5 , in particular, constitues a clear anticipation. In its supplementaries 5.51-5.54 it is spelled out how to cope with the problems posed by ordinary truth-functions, quantification, identity and propositional attitudes, and thesis 5.55 , with its string of commentaries up to 5.56 , provides information highly germane for the task of determining what notations are admissible for clases of Elementarsätze.

The first of Wittgensten's three illustrative ways from thesis 5.501 is clearly admissible also for Elementarsätze: if an Elementarsatz is recognizable as such am Symbol allein, then a finite list of Elementarsätze can also be recognized as such am Symbol allein. The second case is more problematic, though. An Elementarsatz is a concatenation of Names (4.22), but is every concatenation of Names an Elementarsatz? That is, can we have concatenations of Names which are either simply nonsense or nonelementary Sätze? This is a matter of some importance in connection with Wittgenstein's view of expressions containing variables $(3.312,3.317)$. Let us consider an Elementarsatz, that is a certain concatenation of Names, say,

$$
\text { a \# b \# c \# d }
$$

of Names. ${ }^{15}$ For certain Names, among which

c,

an Elementarsatz will result when the gap in

$$
\text { a \# b \# \# d }
$$

is filled with the Name in question. Are there other Names, though, for which either a nonelementary Satz or outright nonsense results when the gap is filled? ${ }^{16}$ The use of a variable

15. Here '\#' is used as a concatenation symbol.

16. Nonsense might reult from attempting to concatenate unconcatenatable Names. The question is only if there are such Names? 
yields a Satzvariable

$$
\text { a \# b \# } \xi \text { d, }
$$

becuase by stipulation (3.316) only such substitutions are considered for which a Satz results. Legitimate postulation of Elementarsatzvariable presupposes that it is decidable an dem Namen allein whether it yields an Elementarsatz when used in gaps such as in the above concatenation of Names. I have not been able to settle this matter from the text of the Tractatus and would not be surprised if it is undetermined there.

As regards the third illustrative method from 5.501 we can be more conclusive: it is definitely to be ruled out as inadmissible for Elementarsätze. The use of a formal law to generate a Formenreihe of Sätze imposes a syntactic hierarchy $(5.252,5.2522)$ and there can be no hierarchies among the Elementarsätze ( 5.556, 5.561), owing to their extreme logical independence.

It seems clear after the above discussion that Wittgenstein intends his Sätze to be inductively generated and that the basic clause in this definition should deal with their dependency on the Elementarsätze. Thus the interpretational challenge put by thesis 6 is to describe the type of definition by induction used there. "Officially" iterations only are allowed, but will not suffice. The following makes the dependency on the Elementarsätze explicit and seems as good a candidate as any to capture Wittgenstein's intention in thesis 6:

\section{Der Satz.}

(0) An Elementarsatz is a Satz.

(i) The result of applying $\mathrm{N}$ to a (legitimately presented) class of Sätze is a Satz.

(ii) There are no other Sätze than those obtained through successive applications of (0) and (i).

Thus presented, the definition has all the features of a proper inductive definition: there are basic, inductive and extremal clauses. 
The inductive clause (i) may be elaborated into something slightly more explicit:

(ia) The result of applying $\mathrm{N}$ to a finite list of Sätze is a Satz.

(ib) The result of applying $\mathrm{N}$ to the values of a Satzvariable $\mathbf{f}(\mathbf{x})$ is a Satz.

(ic) The result of applying $\mathrm{N}$ to the terms of a formal series of Sätze is a Satz.

(id) The result of applying $\mathrm{N}$ to any other legitimately presented class of Sätze is a Satz. ${ }^{17}$

We must, however, take notice of a residual vagueness in (this rendering of) Wittgenstein's thesis 6, when considered as an inductive definition of the formal concept Satz: the question remains whether Elementarsätze (and via clause (0) also Sätze) can be recognized as such am Symbol allein, since the former cannot be logically circumscribed in any further way. In particular, they cannot be inductively generated, owing to the strictures against hierarchies and concomitant internal relations among them. Furhtermore, the definition is impredicative to an extent which exceeds that common to ordinary inductive definitions: the definition itself, especially as given by Wittgenstein in thesis 6 , is clearly an example of a "formal law" in the sense of the third illustrative method from thesis 5.501 and so the result of applying $\mathrm{N}$ to the class of all Sätze is itself a Satz occuring in the listing as given by the formal law. This circularity need not necessarily be a vicious one, though, since the Satz obtained through application of $\mathrm{N}$ to all Sätze is nothing but the contradiction falsum. ${ }^{18}$

Given Wittgenstein's harsh words against Frege and Russell concerning impredicativity (4.1273) some care on his part would not have been out of place here, if only to show that the author of the Tractatus was aware of the lurking impredicativity. The unre-

17. Soames, op.cit., f.n. 2, p. 581, f.n. 21, credits John Etchemendy with the insight that thesis 6 can best be viewed as an inductive definition. His proposal is slightly less comprehensive than the version offered here in that it leaves out the possibility of giving the range of bases by means of a formal law.

18. It can also be obtained using method $2: N(S)=\mathbb{X}\{$ S is a Satz : $\neg S\}$. 
stricted use of 'formal law' constitutes another source of vagueness in the generattion of the Sätze. It would be possible to render this precise if one could give a 'formal law' which generates all formal laws. This has not been done and it is extremly hard to see how it could be done; in the analogous case for arithmetic it is known that the total recursive functions have no recursive universal function, owing, of course, to Cantorian diagonalization.

The idea exemplified by the third illustrative way in 5.501, namely that of applying an infinitary operator to a more or less constructively given class of bases has been used to great effect in the theory of the sub-languages of the infinitary language $\mathrm{L}_{\omega_{1} \omega}$, that is, predicate logic with infinite conjunctions and finite quantifier-prefixes. ${ }^{19}$

Especially in comparison with the virtuosity of this latter technical development Wittgenstein's treatment of the inductive means for generating his Sätze appears primitive: in brief, he does not realise that a Formenreihe, which is either a cyclic series or a progression in PM sense,$^{20}$ is not the right general notion of order to associate with inductive definintions. ${ }^{21}$ The particularly simple case of the inductive generation of the wff's of propositional logic makes this perfectly clear. The order of precedence is not a total and objects can have more than one immediate predecessor: the wff P \& Q has the wff $\mathrm{P}$, as well as the wff $\mathrm{Q}$, as immediate predecssors, but does not in any way dominate the wff $\mathrm{R}$. The ordering corresponding most naturally to an inductive definition is not a total wellordering (of which progressions form an example), but a wellfounded partial ordering. ${ }^{22}$

19. H.J. Keisler, Model Theory for Infinitary Logic, North Holland, Amsterdam, 1971 and J. Barwise, Admissible Sets and Structures, Springer, Berlin, 1975, are the standard references conceming languages of this type. What Dag Prawitz calls 'Propositions' in his article of the name, Theoria 34 (1968), pp. 134-46, or rather the set-theoretic model offered in section 4, pp. 143-44, can reasonably be taken as an infinitary construction of Tractarian Sachverhalte and complexes thereof.

20. See the picture on page 639 of PM, Vol. I, op. cit., f.n. 2 .

21. The inducitve definitions in the Tractatus are approached via the notion 'and so on'; the latter is to be captured via operations and thus the general operational form can be seen as a sort of normal form for inductive definitions.

22. P. Aczel, "An introduction to inductive definitions", Ch. C.8, in: J. Barwise, Handbook of Mathematical Logic, North Holland, Amsterdam, 1977, treats of these matters in a lucid and relaxed way. 
Of the topics listed at the outset of my paper only two remain. The first of these, namely the proper interpretation of the Tractarian equality-sign, is easily dealt with: Wittgenstein (4.241-4.243) denies equality the status of a material propositional function and adopts Frege's Begriffsschrift theory of equality. Thus the sign

$$
\mathrm{a}=\mathrm{b}
$$

expresses that the signs ' $a$ ' and ' $b$ ' are intersubstitutable in Sätze, that is, that they have the same use and accordingly that both signs are the same symbol. It is also used to state nominal definitions in what is claimed to be the Russellian form

$$
a=b \text { Def., }
$$

where $\mathrm{a}$ is the definiens and $\mathrm{b}$ the definiendum. Russell, however, used the opposite order between definiens and definiendum in his definitions. ${ }^{23}$ The order employed in the Tractatus is the one preferred by Frege. ${ }^{24}$ In the Prototractatus, on the other hand, the definitions are cast in the Russellian mould; neither the reason behind this change nor its purpose are clear to me.

The equation in 6.01 lacks a definitional mark and it is the right hand sign, if any, which is already understood: the three-place brackets have been explained, but not the two-place. In view of this circumstance one still might want to treat of the equation as a definitional elucidation. In this equation an operation is then defined by laying down what the result is given a certain base. This value is described in terms of the three-place square-brackets. The Greek variable

here determines a range of Sätze and the square bracket in the RHS of the equation in 6.01 then describes the formal concept of an $\eta-$ Satz,

23. PM, Vol I, op.cit., f.n. 4, p. 11.

24. Begriffsschift, op. cit., f.n. 5, p. 56 and Grundgesetze der Arithmetik, Vol. I, Jena $1893,27$. 
much in the same way that thesis 6 gave the formal concept Satz. The inductive definition of the $\eta$-Sätze is of the pattern exhibited above:

\section{Der $\eta$-Satz.}

(0) Every Satz in the range $\eta$ is an $\eta$-Satz.

(i) The result of applying the operation $\mathrm{N}$ to a range of $\eta-S a ̈ t z e$ is an $\eta$-Satz.

(ii) There are no other $\eta$-Sätze than those obtained through successive applications of (0) and (i).

This, thus, is how, in general, the values of operations are specified. The role of the range $\eta$ must be further elucidated, though, in view of the preamble 6.002:

Ist die allgemeine Form gegeben, wie ein Satz gebaut ist, so ist damit auch schon die allgemeine Form davon gegeben, wie aus einem Satz durch eine Operation ein anderer erzeugt werden kann.

This formulation elaborates that of the rider of 6.01 , where the Übergang from one Satz to another is considered. Both formulations have, I think to be taken cum grano salis; one would certainly expect Wittgenstein's foremost example of an operation, namely the joint negation operation $\mathrm{N}$, to conform to the general operational form. This it will not do when the general form is confined to cases which allow only for bases which consist of one single Satz: the operation $\mathrm{N}$ is, as has been stressed already, a multigrade operation, taking any number of Sätze into a Satz.

An operation is given by an internal relation between (the structures of the facts which serve as Satzzeichen for the relevant) Sätze and as discussed above this relation may be truth-functionally formulated. Thus the relation $\mathrm{R}$ between the base B of Sätze and the Satz $\mathrm{S}$ is a truth-functional one. It must, of course, be many-one. The base B must be presented in an adequate way, perhaps using one of Wittgenstein's three illustrative techniques. In the base B the Satz P, say, occurs and hence a certain relation obtains also between $P$ and $S$. This relation is in a sense derived from the relation $R(B, S)$; when the latter is made fully explicit, for instance as

$$
R(\{\ldots, P, \ldots\}, S)
$$


one sees that the other members of the base serve as parameters in the definition of the relation

$$
Q(P, S)=\text { df. } R(\{\ldots, P, \ldots\}, S) \text {. }
$$

My suggestion is now that Wittgenstein does not primarily deal with the passage from $S a t z$ to $S a t z$, which corresponds to the relation Q, but with the form of the passage from a base B (in which the relevant Satz is included) to a certain Satz, in other words with the operation that corresponds to the relation R. Given that it is certainly legitimate to obtain a Satz from another Satz through application of a many-place operation to the given Satz plus other supplementary Sätze, whose function is merely parametric, Wittgenstein does have to include such cases in his general account of how a Satz can be obtained from another Satz, and this is the reason for the occurrence of a whole base-range of Sätze in the explication of the passage from Satz to Satz. He could, however, have been a bit more explicit about the role of the range which serves to give the bases for the application of $\mathrm{N}$ in the elucidation of the general operational form: the Übergang finds place between a certain, further unspecified, Satz in the range and the $\eta-S a t z$ given on the right in the equation in 6.01 .

The two-place square brackets, to the left in this equation, on the other hand, can readily be interpreted as providing a variable-binding device of the same kind as that discussed above for the three-place square-brackets. Thus, in modern notation, using capital "X" as a class-variable ranging over classes of Sätze, an appropriate version would be:

\section{$[\lambda \mathrm{XN}(\mathrm{X})](\eta)$}

Accordingly we can now describe the general form of transtion from a given Satz p to another Satz in the following way:

0. Choose a range $\xi$ of Sätze.

1. Choose a certain $\xi$-Satz.

2. Define an operation on ranges of Sätze by putting its result equal to the $\xi$-Satz chosen at step 1 .

3. Choose a range $\eta$ of Sätze which contains the given Satz p. 
4. Apply the operation defined in step 2 to the range $\eta$ chosen at step 3 .

5. The result is a Satz q obtained in the most general way from $p$.

With this our interpretative task has been resolved.

In view of the matters discussed in the present paper Gödel's stern words on standards of syntactic precision may be cited; he found that PM "presents in this respect a considerable step backwards from Frege" and, mutatis mutandis, this verdict seems applicable also to Russell's erstwhile pupil Wittgenstein. ${ }^{25}$ Indeed, the Tractarian sign-language is hardly one "in which everything fits", so could we not turn his own tables on the author of the Tractatus? Does he, in view of thesis 4.1213 , have a correct logical doctrine? One the other hand, we must not be too severe: Wittgenstein was writing as a pioneer. With the benefit of seventy years of technical hindsight at our disposal it is possible to detect a few places where the Tractarian treatment goes astray. When Wittgenstein wrote even Skolem's famous paper on recursive definitions was yet to appear. ${ }^{26}$

This brevity of explanation, and the earlier instances of ill-designed notations, such as when the placemarking and variable-binding roles of variables are confused, are symptomatic of Wittgenstein's treatment of formal matters: compared to his masterly command of the issues within the philosophy of logic, his grasp of how to design a complex formalism is clearly not as firm. The difficulty and the magnitude of the latter task is often overlooked. The list of logicians who have tried to construct substantial interpreted formal languages adequate for sizable parts of mathematics, but who failed in their early attempts, is impressive: it comprises, among others, Frege, Church, Curry, Quine and Martin-Löf. The combination of great

25. "Russell's Mathematical Logic", in: P.A. Schilpp (ed.), The Philsophy of Bertrand Russell, Library of living philsophers, vol. 5, Northwestern University Press, Evanston, 1944, p. 126.

26. "Begründung der elementaren Arithemetik durch die rekurrierende Denkweise ohne Anwendung scheinbarer Veränderlicher mit unendlichen Ausdehnungsbereich", Vidensskapsselskapets Skrifter, I. Matematisknaturvidenskabelig Klasse, 1923, no. 6 (Kristiania,1923). English trans. in: J. van Heijenoort, From Frege to Gödel, Harvard U.P., 1967, pp. 303-333. 
logico-philosophical insight and skill at the design of formalisms is a very rare one: Frege provides the only example among the great formal logicians in the first half of our century. Peano was a great designer of logical notation, but did not have the corresponding philosophical power. The author of the Tractatus, on the other hand, constitutes the finest example of a philosopher whose technical formal capacities do not reach the outstanding level of his logicophilosophical thinking. 